\title{
Dijker en Limperg voorbij
}

\author{
Willem Buijink
}

\author{
\begin{tabular}{l|l|l|l} 
Received 2 August 2021 & Accepted 23 August 2021 & Published 2 September 2021
\end{tabular}
}

Het is verbazingwekkend hoe groot de impact van accountantscontrole-onderzoek van bijna 100 jaar oud nog is in Nederland. Ik bedoel de impact ervan op discussies over de Nederlandse accountancysector en op het Nederlandse accountantscontrole-onderzoek en -onderwijs. Het is ook verontrustend.

Een recent rapport van de Stuurgroep Publiek Belang, van de Nederlandse Beroepsorganisatie van Accountants (NBA), over 'accountantscontrolekwaliteit' citeert prominent werk van Limperg uit 1932 (NBA 2018). Het recente eindrapport van de Commissie Toekomst Accountancysector (CTA 2020) begint met een citaat van Dijker uit 1930. Een recent interview in het magazine Accountant met NBA-voorzitter Van der Vegte over de stand van zaken in de accountancysector, gaat grotendeels over Limpergs jaren '30 inzichten betreffende accountantscontrole-onderzoek (Quadackers and Ter Wolbeek 2020). Nog een recent interview in het magazine Accountant (Quadackers 2021) gaat over een nieuw filosofievak in het accountantscontrole-onderwijs aan Nyenrode. In dat vak komt de vraag wat accountantscontrole is aan de orde. Limpergs jaren ' 30 omschrijving wordt genoemd in het interview: hedendaagse omschrijvingen niet. In een recente Tweede Kamer commissievergadering over de accountancysector (2020) wordt alleen Limperg genoemd als accountancy-onderzoeker.

In de meest recente tien MAB-jaargangen, terug tot 2011, wordt Limperg 30 maal genoemd in een artikel. Van die 30 verwijzingen gaan er, af te lezen aan de titels van de artikelen, 24 over accountantscontrole (en 6 over verslaggeving). Dat is vaak. Want in dezelfde periode worden hedendaagse vooraanstaande accountantscontrole-onderzoekers als Knechel en Francis 48 en 45 maal genoemd in MAB artikelen: Salterio en Trotman 14 en 12 maal. Vooraanstaande accountantscontrole-onderzoekers uit de Lage Landen als Vanstraelen en Willekens 27 en 13 maal.

Limperg droeg ook bij aan het bedrijfseconomische organisatie-, financiering- en marketingonderzoek. Van de 30 verwijzingen naar Limperg betreffen er maar twee deze gebieden: allebei organisatie-artikelen. De hedendaagse impact van Limpergs onderzoek is dus met name groot als het over accountantscontrole gaat. In de andere bedrijfseconomische gebieden is die impact er niet meer, ook niet op het terrein van externe en interne verslaggeving.

Ik spreek over 'onderzoek' door Limperg en Dijker. Beiden waren als academicus actief. Limperg als voltijds hoogleraar in Amsterdam en Dijker, deeltijds, in Rotterdam, eerst als lector en later als buitengewoon hoogleraar. Ze namen dus als wetenschapper deel aan de debatten over accountantscontrole-methodieken, de accountancysector en de regulering daarvan.

Is het goed dat 100 jaar oud accountantscontrole-onderzoek nog zo prominent figureert in discussies over de Nederlandse accountantscontrole-praktijk, de accountancysector en in het Nederlandse accountantscontrole-onderwijs?

Nee.

In de eerste plaats is het hedendaagse accountantscontrole-onderzoek heel anders van aard dan het onderzoek van de wetenschappers Dijker en Limperg. Limperg, met name, redeneerde normatief als micro-econoom over de accountancysector. Hij legde uit 'hoe' accountantscontrole rationeel, 'economisch efficiënt', in elkaar gezet moest worden ('normatieve regelen'). Dat bleef ook zo, bij hem en bij volgelingen, in de tijd direct rond de Tweede Wereldoorlog waarin de micro-economie zelf, te beginnen bij het ontstaan van econometrie en, heel expliciet, na Friedman (1953), nadrukkelijk empirisch werd. De 'oorzaak en effect' (causale) vraag m.b.t. fenomenen in een economie, en het toetsen van met theorie gefundeerde antwoorden daarop kwam centraal te staan. Tegen de jaar '60 van de vorige eeuw nam deze benadering ook de bedrijfseconomie deelgebieden Financiering, Organisatiekunde en Marketing in. In beide laatste gebieden gebeurde dat ook onder invloed van de empirische sociale psychologie. Accounting- (verslaggeving) en accountantscontrole-onderzoek transformeerden als laatsten. In Nederland gebeurde dat pas in de vroege jaren ' 90 aan de Maastrichtse universiteit. Ik schreef daar eerder een MAB 
column over: 'Vrolijk' (Buijink 2014). Het hedendaagse empirische accountantscontrole-onderzoek heeft het normatieve onderzoek à la Dijker en Limperg verdrongen. Het is onjuist en onverstandig de indruk te wekken dat dat niet zo is. Er is geen reden meer om het normatieve onderzoek van Dijker en Limperg, als het gaat om het begrijpen van accountantscontrole en de accountancysector, en de vormgeving en regulering ervan, in te roepen of na te volgen. Voor een goed begrip: normatieve innovaties in accountantscontrole-methodiek en in de regulering van de accountancysector zijn belangrijk. Wat het hedendaagse onderzoek toevoegt is het toetsen van de uitkomsten van dat innoveren.

Een tweede, gerelateerd, probleem ontstaat doordat het leggen van nadruk op het Dijker- en Limperg-onderzoek gemakkelijk het beeld ontstaat dat zonder Dijker en Limperg een accountancysector in Nederland niet tot stand zou zijn gekomen. Dat is onjuist. Precies op basis van micro-economie kan goed voorspeld worden, en getoetst worden, (a) waarom de functie van extern accountant ontstaat en (b) waarom er verenigingen van accountants ontstaan (die een nuttig kwaliteitslabel verschaffen) en wat de effecten daarvan zijn. Daar bestaan heldere toetsende studies over. Limperg (1933) legt (a) in zijn MAB-artikelenreeks ook micro-economisch uit. Maar hij doet dat op normatieve wijze en toetsing van het antwoord wordt door hem ook niet aanbevolen. Limperg ging niet expliciet in op (b). Zonder Dijker en Limperg was de accountancysector, en het accountantsberoep, in Nederland ook ontstaan. Ook belangrijk: veel meer 'helden' dan Dijker en Limperg, ook in andere verenigingen dan hun NIVA, hebben in de ontwikkeling ervan een rol gespeeld.

Een derde, ernstiger, reden om het accountantscontrole-onderzoek à la Dijker en Limperg te verlaten is deze. Regelgevers en toezichthouders maken misbruik van de normatieve onderzoeksbenadering van Dijker en Limperg. Ik bedoel hier het Ministerie van Financiën (MinFin), de relevante Europese Commissie Directoraten en de NBA (de plekken waar accountancysector-regels worden bedacht), de Autoriteit Financiële Markten (AFM), en gerelateerde adviescommissies zoals de Monitoring Commissie Accountancy (MCA) en de CTA. Door het onderzoek van Dijker en Limperg steeds sterk in de schijnwerper te plaatsen, wordt het gemakkelijk hedendaags empirisch accountantscontrole-onderzoek links te laten liggen. Vanuit de economische theorie over regulering is dat overigens te verwachten. Toetsing van het regulerend werk van regelgevers en toezichthouders in de accountancysector, vooraf (voorspellend) en achteraf, wordt door hen natuurlijk lastig gevonden. Een paar voorbeelden. Het 53-maatregelen-rapport van de NBA uit 2014 gebruikt voor de onderbouwing van de voorge- stelde maatregelen geen bestaand empirisch onderzoek. Ik maakte daar eerder, met Dassen (Buijink and Dassen 2015), in het MAB bezwaar tegen. De MCA (2020) stelde dat empirisch onderzoek de accountancysector niet vooruit kàn helpen: zie daarover mijn eerdere 'Non-Replicable ?' MAB-column (Buijink 2018). In het AFM 'Kwetsbaarheden'-rapport (AFM 2018) wordt, 'omdat onderzoek altijd achterloopt op de praktijk', anekdotisch materiaal gebruikt als evenwaardig aan regulier onderzoek. De AFM organiseert vooraf en achteraf geen kritiek op haar onderzoek. Door MinFin en het parlement wordt serieus onderzoek naar de echte frequentie (die is laag) van accountantscontrole-schandalen niet gelezen. De frequentie wordt met retoriek als 'hoog' voorgesteld (zie daarover mijn eerdere MAB-column 'Retorica?'; Buijink 2015). Het Ministerie van Financiën organiseerde een evaluatie van de WTA (Eijkelenboom and Hijink 2014). Maar die evaluatie gebruikte niet de beste beschikbare onderzoeksbenaderingen. De Kwartiermakers legden recent een goed actueel overzicht van Bédard and Schatt (2020) van onderzoek naar de wenselijkheid van 'joint audits' terzijde. Ze regelden een nieuw onderzoek. Expliciet vragend om ook verwijzingen naar normatief onderzoek. Het blijven proclameren van de prominentie van het onderzoek van Dijker en Limperg is consistent met een vermoeden dat dit een nuttig 'scherm' schept dat normatief beleid door de regelgevers en toezichthouders mogelijk maakt. Zij hoeven zich dan niet 'evidentie geïnformeerd' te gedragen.

Er is een kleine hoop dat in de nabije toekomst het normatieve Limperg-en-Dijker-onderzoek door regelgevers en toezichthouders verlaten zal worden. Alhoewel het CTA-rapport met een Dijker-citaat begint, is de hoofdtoon van het rapport anders, Het belang van goed feitelijk en causaal onderzoek dat nuttig licht werpt, 'evidentie geinformeerd', op de Nederlandse accountancysector staat voor de CTA vast. Een van de centrale CTA-deelstudies, de ECRI-literatuurstudie (Maasland 2019), laat dat ook zien. Dat is een begin. Bovendien, wellicht is dit een teken: Limperg wordt ook geciteerd in het CTA-rapport: twee maal: maar zijn naam wordt twee maal verschillend verkeerd gespeld.

Waardering, dogmen-historisch, voor het bijna 100 jaar oude accountantscontrole-onderzoek van Dijker en Limperg is zeer gerechtvaardigd. Maar gebruik ervan nu niet meer. Het accountantscontrole-onderzoek in de wereld en Nederland sinds Dijker en Limperg is van benadering veranderd en die benadering verschaft een veel beter inzicht in de ontwikkeling en de werking van de accountancysector, en in de regulering ervan. Regelgevers en toezichthouders in Nederland moeten nu echt tot dit besef komen.

- Willem Buijink is Senior Research Fellow Accounting aan de Open Universiteit. Hij is daarnaast emeritus Hoogleraar aan Tilburg Universiteit en aan de Open Universiteit. 


\section{Literatuur}

- AFM [Autoriteit Financiële Markten] (2018) Kwetsbaarheden in de structuur van de accountancysector. AFM, Amsterdam. https://www. afm.nl/nl-nl/professionals/nieuws/2018/nov/kwetsbaarheden-structuur-accountancysector

- Bédard J, Schatt A (2020) Economic consequences of joint audits. Practice note. The Foundation for Auditing Research. https://foundationforauditingresearch.org/files/joint-audit.pdf

- Buijink WFJ (2014) Vrolijk ! Maandblad Voor Accountancy en Bedrijfseconomie 88(1/2): 4-6. https://doi.org/10.5117/mab.88.31229

- Buijink WFJ (2015) Retorlca? Maandblad voor Accountancy en Bedrijfseconomie 89(1/2): 4-6. https://doi.org/10.5117/mab.89.31235

- Buijink WFJ (2018) Non-replicable? Maandblad voor Accountancy en Bedrijfseconomie 92(7/8): 195-196. https://doi.org/10.5117/ mab.92.30206

- Buijink WFJ, Dassen RJM (2015) Bedrijfseconomie en de Werkgoep toekomst accountantsberoep 2014. Maandblad Voor Accountancy en Bedrijfseconomie 89(3): 102-111. https://doi.org/10.5117/ mab.89.31261

- CTA [Commissie Toekomst Accountancysector] (2020) Vertrouwen op controle: Rapport van de Commissie toekomst accountancysector. https://www.rijksoverheid.nl/documenten/kamerstukken/2020/01/30/ vertrouwen-op-controle-eindrapport-van-de-commissie-toekomst-accountancysector

- Eijkelenboom EVA, Hijink JBS [kernredactie] (2014) Bouwen aan vertrouwen: Evaluatie van de Wet toezicht accountantsorganisaties ('Wta') (bijlage bij 33977, nr. 2). IvO/ ICFO, Erasmus Universiteit Rotterdam (in opdracht van het Ministerie van Financiën). https:// www.parlementairemonitor.nl/9353000/1/j9vvij5epmj1 ey0/vjnmd2kh6fu8

- Friedman M (1953) The methodology of positive economics. In: Essays in positive economics (1966) Chicago University of Chicago Press, 3-16, 30-43. https://www.sfu.ca/ dandolfa/friedman-1966.pdf

- Limperg Th (1932a) De functie van den accountant en de leer van het gewekte vertrouwen. Deel I. Maandblad voor Accountancy en Bedrijfseconomie 9(2): 17-20. https://doi.org/10.5117/mab.9.14573
- Limperg Th (1932b) De functie van den accountant en de leer van het gewekte vertrouwen. Deel II. Maandblad voor Accountancy en Bedrijfseconomie 9(9): 151-154. https://doi.org/10.5117/mab.9.11005

- Limperg Th (1933) De functie van den accountant en de leer van het gewekte vertrouwen. Deel III. Maandblad voor Accountancy en Bedrijfseconomie 10(9): 173-177. https://doi.org/10.5117/mab.10.11015

- Maasland E (2019) Literatuurstudie naar kwaliteitsverbeterende maatregelen in de accountancysector. ECRI, Erasmus Universiteit Rotterdam. https:/ecri.nl/wp-content/uploads/2020/02/ECRi_rapport_sept.-2019.pdf

- MCA [Monitoring Commissie Accountancy] (2020) Eindrapport Monitoring Commissie Accountancy: Spiegel voor de accountancysector. MCA, Amsterdam. http://www.monitoringaccountancy. nl/wp-content/uploads/2020/01/Eindrapport-Monitoring-Commissie-Accountancy-140120.pdf

- NBA [Koninklijke Nederlandse Beroepsorganisatie van Accountants] (2014) In het publiek belang: Maatregelen ter verbetering van de kwaliteit en onafhankelijkheid van de accountantscontrole. Rapport van de Werkgroep Toekomst Accountantsberoep. NBA, Amsterdam. https://www.nba.nl/globalassets/projecten/in-het-publiekbelang/in_het_publiek_belang_rapport_25_september_2014.pdf

- NBA [Koninklijke Nederlandse Beroepsorganisatie van Accountants] Stuurgroep Publiek Belang (2018) Waar het om gaat. Kompas voor controlekwaliteit. White paper. https://www.nba.nl/globalassets/projecten/in-het-publiek-belang/green-paper-and-white-paperaudit-kwaliteit/white-paper_waar-gaat-het-om.pdf

- Quadackers L, Ter Wolbeek M (2020) Van der Vegte over Limperg. "We kunnen aan de hand van Limpergs Leer nog zaken verbeteren". Accountant 2020(6): 10-14, 17. https://www.accountant.nl/globalassets/accountant.n1/blad/2020-nr.-6/acc_2020_nr6_van_der vegte_over_limperg.pdf

- Quadackers L (2021) 'Waarom doen we wat we doen'. Accountant 2021(2): 10-15. https://www.accountant.nl/globalassets/accountant. n1/blad/2021-nr.-2/acc-2021-nr2-waarom-doen-we-wat-we-doen.pdf

- Tweede Kamer commissievergadering over de accountancysector (2020) Tweede Kamer Commissie Financiën vergadering over de accountancysector van 28 september 2020. https://www.tweedekamer.nl/debat_en_vergadering/commissievergaderingen/details?id=2020A01525 